\title{
Article \\ Maintenance of Maternal Breastfeeding up to 6 Months: Predictive Models
}

\author{
Esmeralda Santacruz-Salas 1,2,3 (D), Antonio Segura-Fragoso ${ }^{1}$, Diana P. Pozuelo-Carrascosa 2,3,4 (D), \\ Ana Isabel Cobo-Cuenca $2,3,4,5, * \mathbb{D}$, Juan Manuel Carmona-Torres $2,3,4,5$ (D) and José Alberto Laredo-Aguilera $2,3,4,5$ (D)
}

check for

updates

Citation: Santacruz-Salas, E.;

Segura-Fragoso, A.;

Pozuelo-Carrascosa, D.P.;

Cobo-Cuenca, A.I.; Carmona-Torres,

J.M.; Laredo-Aguilera, J.A.

Maintenance of Maternal

Breastfeeding up to 6 Months:

Predictive Models. J. Pers. Med. 2021,

11, 396. https://doi.org/10.3390/

jpm11050396

Academic Editor: Monique J. Roobol

Received: 25 March 2021

Accepted: 6 May 2021

Published: 11 May 2021

Publisher's Note: MDPI stays neutral with regard to jurisdictional claims in published maps and institutional affiliations.

Copyright: (c) 2021 by the authors. Licensee MDPI, Basel, Switzerland. This article is an open access article distributed under the terms and conditions of the Creative Commons Attribution (CC BY) license (https:/ / creativecommons.org/licenses/by/ $4.0 /)$.
1 FACSALUD (Faculty of Health Sciences), Av. Real Fábrica de la seda, s/n., Talavera de la Reina, 45600 Toledo, Spain; esmeralda.santacruz@uclm.es (E.S.-S.); Antonio.Segura@uclm.es (A.S.-F.)

2 Multidisciplinary Research Group in Care (IMCU), UCLM. Av. Carlos III s/n., 45071 Toledo, Spain; dianap.pozuelo@uclm.es (D.P.P.-C.); juanmanuel.carmona@uclm.es (J.M.C.-T.); josealberto.laredo@uclm.es (J.A.L.-A.)

3 Department of Nursing, Physiotherapy and Occupational Therapy, University of Castilla la Mancha (UCLM), 45071 Toledo, Spain

4 Faculty of Physiotherapy and Nursing of Toledo, University of Castilla la Mancha (UCLM) Av. Carlos III s/n., 45071 Toledo, Spain

5 Maimónides Institute for Biomedical Research Córdoba (IMIBIC), 14004 Córdoba, Spain

* Correspondence: anaisabel.cobo@uclm.es; Tel.: +34-925268800 (ext. 5818)

\begin{abstract}
Background: There is evidence of the benefits of exclusive breastfeeding (EBF) but maintaining EBF for the minimum recommended time of 6 months is challenging. Aims: This study aimed to determine the prevalence of breastfeeding types in a Spanish setting, explore the influencing factors, and analyze the relationships between the reasons for EBF cessation and the EBF durations achieved. Method: This longitudinal descriptive study included 236 healthy children with standard weight followed up by the public health system. A baseline survey and three telephone interviews $(1,3$, and 6 months) were conducted. Results: The prevalence of EBF at 6 months was $19.49 \%$. The mean age of the mothers was $32.3( \pm 5.3)$. The variables influencing EBF maintenance were the prior decision to practice EBF ( $p=0.03$ ), the belief that EBF is sufficient $(p=0.00)$, not offering water or fluid to the child $(p=0.04)$, delaying pacifier use $(p<0.001)$, a longer gestation time $(p=0.05)$, and previous experience with practicing EBF for more than 6 months $(p=0.00)$. The reason for the earliest EBF cessation (mean $52.63 \pm 56.98$ days) was the mother's lack of self-efficacy $(p=0.05)$. Conclusion: Knowing the reasons for EBF cessation among mothers is important for helping mothers and preventing early weaning. A safe environment and support can prevent early weaning.
\end{abstract}

Keywords: exclusive breastfeeding; breastfeeding; breastfeeding support; early breastfeeding cessation; breastfeeding difficulties; lactation; child health; motivation; weaning

\section{Introduction}

Breastfeeding (BF) is considered the ideal diet for a newborn for both nutritional and immunological support and as a beneficial practice for the mother and child [1-3]. This practice not only provides the best diet but also contributes in the short, medium, and long term to the newborn's emotional, psychological, nutritional, and developmental needs. BF maintained for more than 3 months reduces the risk of otitis media $(77 \%)$, atopic dermatitis $(42 \%)$, asthma (40\%), and respiratory infections (75\%) [4]. In addition, BF maintained for more than 6 months is associated with a $20 \%$ decrease in the risk of leukemia and a $36 \%$ decrease in the risk of sudden death [5]. The long-term benefits associated with BF, such as a lower incidence of childhood morbidity (obesity and diabetes), a two-third reduction in mortality in children aged under 5 years, and better intellectual and motor development scores in children, have been observed [6]. Among mothers who breastfeed, there is also evidence of a lower risk of certain diseases, such as obesity and breast and ovarian cancer, with an estimated reduction of almost 20,000 deaths from breast cancer $[2,3,7]$. The decrease 
in maternal and child morbidity and mortality from the practice of BF is combined with improvements in labor productivity, nonhealth costs, and environmental benefits. BF also entails significant economic savings for families and health systems. Therefore, the entire society benefits [8-10]. This evidence confirms the superiority of BF and supports the need to promote and preserve optimal BF practices.

Despite the health policies and programs that have been implemented, the global rates of $\mathrm{BF}$ are still far from the established goals. The global target for 2025 is for at least $50 \%$ of mothers to practice exclusive breastfeeding (EBF) for the first 6 months [11]. The World Health Organization (WHO) recommends BF until at least 6 months of age and its maintenance along with complementary foods until 2 years of age [12,13]. At the international level, the rates of EBF at 6 months range between $15.2 \%$ and 21\% [14].

The practice of $\mathrm{BF}$ is a sociological phenomenon with multiple influential factors, especially during the first months. According to Rollins et al. (2016), the practice of BF can be affected by interventions in health systems, communities, and family homes; better results are observed with a combination of all three [15].

BF is an effective tool for improving overall health [13]; therefore, mothers have a high initial intention to breastfeed for the minimum recommended time. However, many mothers cease BF early [16]. In the search for information explaining this phenomenon, we spent several years studying the most influential reasons and variables. Most studies independently analyze the impact of the reasons or causes of cessation and/or sociodemographic factors that influence the onset, maintenance, or cessation of BF [17-21]. The results show that the most influential variables are the perception that the child is hungry, hypogalactia, use of accessories, such as a pacifier, and return to work [17,18,22-24]. However, we did not find many studies in our search that analyzed the relationship between the duration of EBF and/or its early cessation and the reasons for cessation mentioned by mothers [25]. The reasons are varied and depend on the time when the mothers decided to cease BF. Due to the benefits described above, it is considered necessary to further explore the factors that contribute to mothers' success or failure in BF at each stage.

The main objective of this study was to prospectively analyze the epidemiological factors associated with the maintenance of BF during the recommended minimum period of 6 months. The secondary objectives were to (a) determine the prevalence of the different types of BF practiced in a Spanish setting and (b) determine the relationships between the reasons for EBF cessation before 6 months and the EBF durations achieved.

\section{Materials and Methods}

\subsection{Study Setting and Sample}

This prospective cohort study consecutively included women who had given birth to a healthy newborn weighing more than $2.5 \mathrm{~kg}$ at a gestational age between 37 and 42 weeks. The exclusion criteria were as follows: (a) abnormal health situations after delivery requiring medical examination for complications, hospital admission, or separation of the mother from the newborn; (b) multiple births; (c) positive neonatal metabolic screening results; and (d) lack of follow-up and/or health checks through the public health system. In Spain, newborn health screenings are performed through the health system for free. All newborns included in the study had to attend these visits to ensure that health professionals collected their clinical information and information related to feeding.

A minimum sample size of 230 women (46 in the EBF group and 184 in the non-EBF group) was estimated based on a pilot study conducted in our setting [10]. The sample size was calculated using the statistical program Epidat 3.1 (Galicia, v.4.1. http:/ / dxsp.sergas.es. Accessed on 18 April 2021) with an alpha error of $5 \%$ and beta of $20 \%$.

A flowchart of the final participant inclusion and reasons for inclusion is shown in Figure 1. 


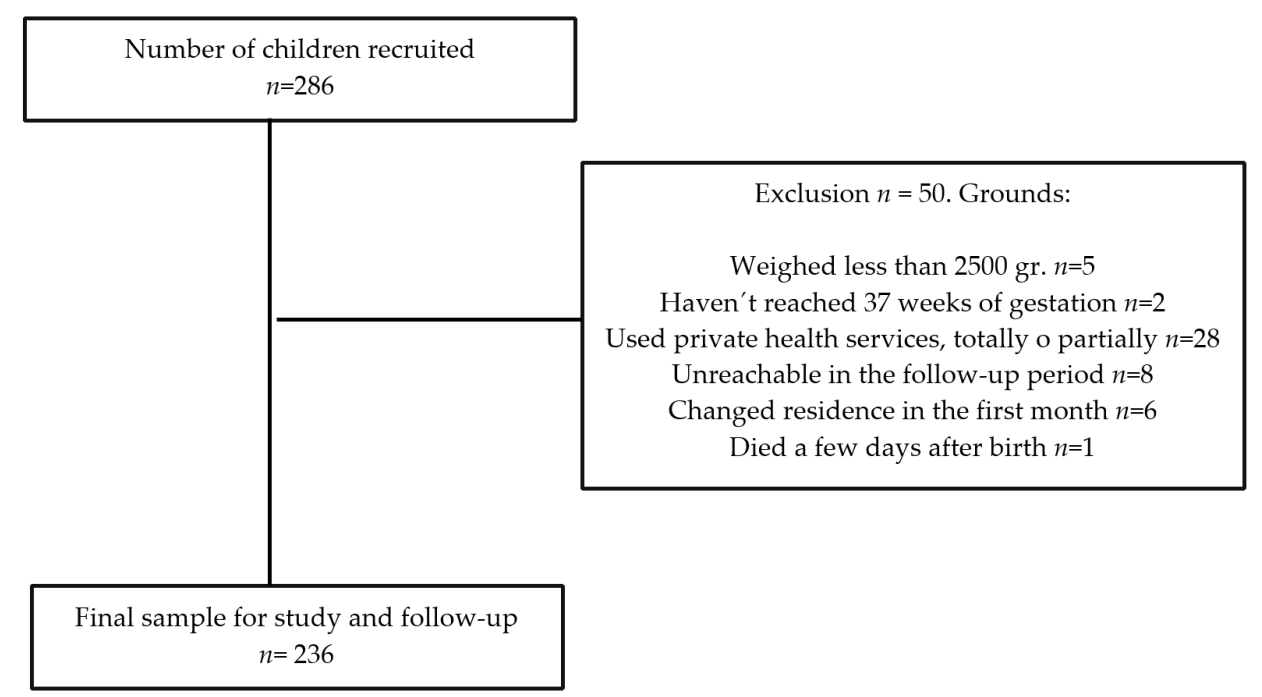

Figure 1. Flowchart of study participants.

\subsection{Study Variables}

The dependent variable, i.e., EBF, was defined as an infant receiving only breast milk, except for oral rehydration solution (ORS) or drops and syrups consisting of vitamins, minerals, or medicines when necessary. Mixed feeding (MF) was defined as an infant receiving certain amounts of both breast milk and formula. Formula feeding (FF) was defined as an infant receiving exclusively formula.

The remaining variables were classified as (a) the sociodemographic and individual characteristics of the mothers and children (age, nationality, educational level, employment status, civil status, sex of the child, and maternity leave); (b) clinical variables potentially related to the practice of $\mathrm{BF}$ (previous number of children, gestation time, type of delivery, type of anesthesia, child birth weight, pacifier use, previous experience with $\mathrm{BF}$, previous decision to practice $\mathrm{BF}$, and previously decided duration of $\mathrm{BF}$ ); and (c) variables related to the family environment or directly related to the practice of $\mathrm{BF}$ (believing that the child is hungry after $\mathrm{BF}$, having offered bottles of water or ORS in the hospital, having offered bottles of formula, having had problems with the practice of $\mathrm{BF}$, having solved the problems that occurred, reasons for introducing FF, from whom BF counseling was received, and partner's opinion regarding BF). Among the reasons mentioned by the mothers for EBF cessation, the following were identified:

(a) Cessation of EBF due to the introduction of solid foods, i.e., "by the recommendation of a health professional" or "the mother's decision";

(b) Cessation of EBF due to the introduction of the bottle, i.e., "by recommendation of a health professional", "influenced by the social or family environment", "the child is not gaining weight according to the standard criteria for age", "work reasons", "the child is still hungry", and" problems with breastfeeding".

The variables "believing that the child is hungry after BF" and "the child is not gaining weight according to the standards for age" were used to identify the mother's BF self-efficacy.

\subsection{Measuring Procedures and Instruments}

To collect the data from the sample, a personal interview was conducted with the mother during the postpartum period at the hospital using an ad hoc questionnaire. During the 6 months of follow-up, another three interviews were conducted by telephone at 1 month, 3 months, and 6 months (interval +/ - 10 days) to compare the prevalence of different types of breastfeeding and collect information regarding pacifier use, return to work, and exact time of the introduction of another type of food. The remaining clinical information and/or information potentially related to the practice of BF was obtained 
from the electronic records of the clinical histories collected by the health workers at the follow-up visits of the newborn health program. The information collected via telephone was used to compare the prevalence of different types of breastfeeding.

\subsection{Statistical Analysis}

For the statistical analysis, SPSS Statistics v. 24.0 (IBM Corp., Armonk, NY, USA) was used. The use license belonged to the University of Castilla-La Mancha.

A descriptive analysis of the variables of interest (EBF, MF, FF, and their duration up to 6 months) was performed using counts $(n)$ and proportions (\%) for the qualitative variables and the mean $(\mathrm{m})$ and standard deviation $(\mathrm{SD})$ for the quantitative variables. The Kolmogorov-Smirnov test was conducted to determine the normality of the data, and Levene's test was conducted to determine the homogeneity of variance. An inferential analysis was performed to determine the relationship between the variables using a chisquared test $\left(\chi^{2}\right)$ for the qualitative variables and Student's t-test for the quantitative variables (normal distribution) or the Mann-Whitney test (nonnormal distribution). The maintenance of EBF was assessed according to the mother's belief and supplementation of BF with water or ORS using Kaplan-Meier curves. The variables significantly associated with the maintenance of EBF for 6 months were included in the multivariate logistic regression model. An unadjusted logistic regression model was also constructed for the women who had previously had children to determine the association between previous experience with EBF and maintenance of EBF for 6 months. The odds ratios and their 95\% confidence intervals were calculated. All hypothesis comparisons were two-tailed, and statistical significance was accepted at $p<0.05$.

\subsection{Ethical Considerations}

This study was approved by the Ethics and Legislation Committee of Hospital Virgen de la Salud (CEITO. number: 74. Date: 6/06/2014). All mothers who decided to participate in the longitudinal study were informed of its content and objectives. All participating mothers signed an informed consent form.

\section{Results}

In total, 236 women and their newborns aged 0 and 6 months were included in the study. The prevalence of the different types of breastfeeding practiced by all mothers in the sample (236) observed at each of the cutoff points analyzed during the 6-month follow-up are shown in Figure 2. In total, 37 (15.7\%) women practiced FF, and nine women (4.52\%) practiced MF throughout the 6-month follow-up. Of the 165 women who practiced BF at some point, only $47(19.92 \%)$ practiced BF during the full 6 months. Despite having practiced EBF, $38(16.10 \%)$ women offered solid foods before 6 months.

The $47(19.92 \%)$ women who practiced EBF during the 6-month follow-up formed the actual study sample. The subsequent analyses and evaluations were carried out in this group of women.

\subsection{Maintenance of EBF}

The sociodemographic and clinical characteristics of all women who practiced EBF for 6 months and their children are described in Table 1. 


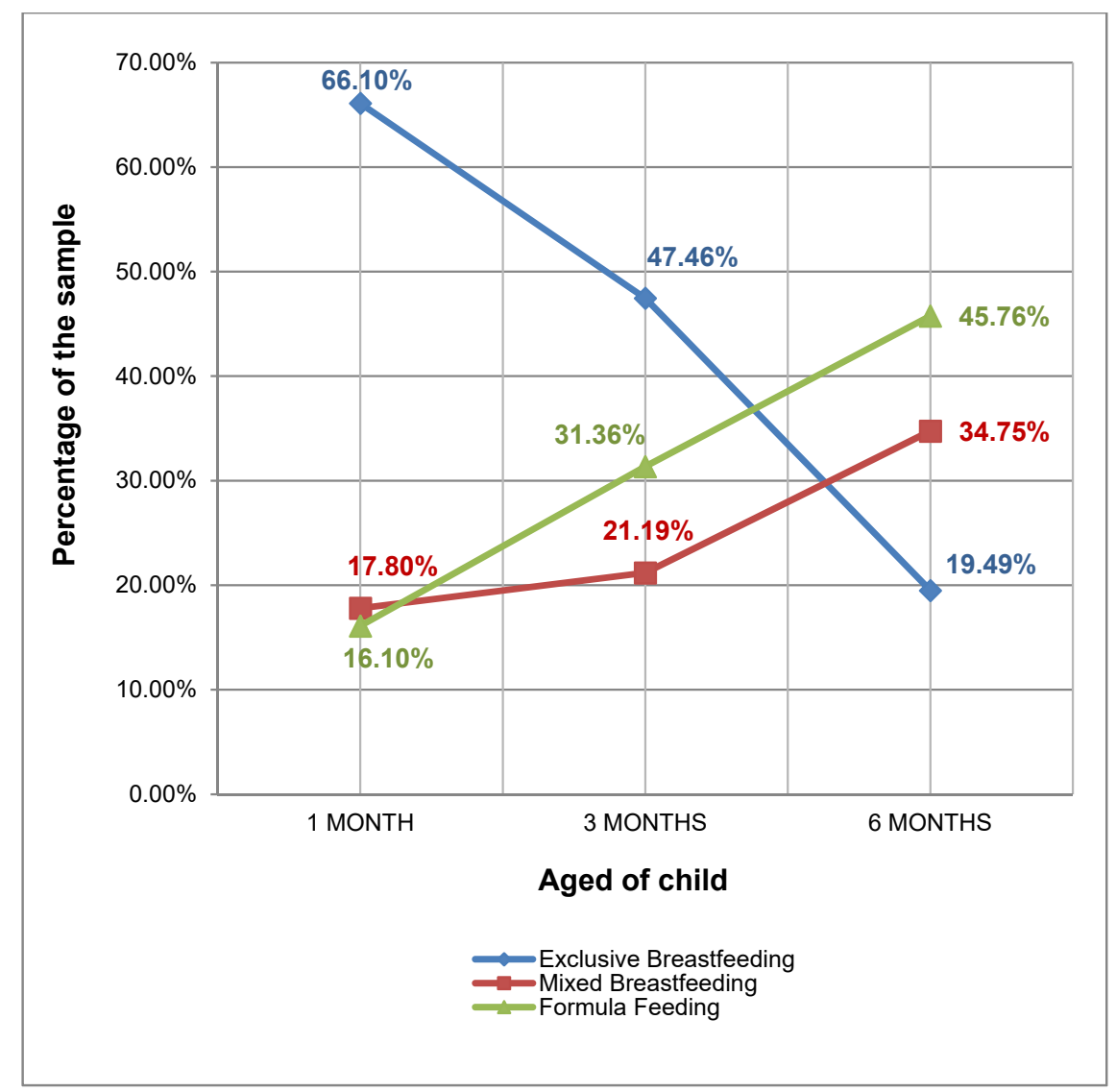

Figure 2. Prevalence of breastfeeding types for 6 months.

Table 1. Characteristics of the mother-child pairs participating in the study and their influence on the maintenance of exclusive breastfeeding for 6 months.

\begin{tabular}{|c|c|c|c|}
\hline \multirow[t]{2}{*}{ Variables } & $\begin{array}{c}\text { Not Exclusive Breastfeeding for } \\
6 \text { Months }\end{array}$ & $\begin{array}{c}\text { Exclusive Breastfeeding for } \\
6 \text { Months }\end{array}$ & \multirow[t]{2}{*}{${ }^{*} p$} \\
\hline & $n(\%)$ & $n(\%)$ & \\
\hline \multicolumn{4}{|c|}{ Social and Individual Maternal, Infant O Mother-Child Factors } \\
\hline \multicolumn{4}{|l|}{ AGE OF THE MOTHER } \\
\hline Up to 30 years & $57(30.16)$ & $13(27.7)$ & 0.73 \\
\hline$>$ than 30 years & $132(69.8)$ & $34(72.3)$ & \\
\hline \multicolumn{4}{|l|}{ NATIONALITY } \\
\hline Spanish & $155(82.01)$ & $42(89.4)$ & 0.23 \\
\hline Foreign & $34(17.99)$ & $5(10.6)$ & \\
\hline \multicolumn{4}{|l|}{ EDUCATION LEVEL } \\
\hline Primary school & $51(26.98)$ & $14(29.8)$ & 0.68 \\
\hline Secondary school or higher & $138(73.02)$ & $33(70.2)$ & \\
\hline \multicolumn{4}{|l|}{ LIVE WITH YOUR PARTNER } \\
\hline Yes & $183(96.83)$ & $47(100)$ & 0.18 \\
\hline No & $6(3.17)$ & $0(0)$ & \\
\hline \multicolumn{4}{|l|}{ MARITAL STATUS } \\
\hline Married or with partner & $114(60.32)$ & $33(70.2)$ & 0.19 \\
\hline Other situations & $75(39.68)$ & $14(29.8)$ & \\
\hline \multicolumn{4}{|l|}{ WORK SITUATION } \\
\hline Employed & $97(51.32)$ & $18(38.3)$ & 0.10 \\
\hline Unemployed & $92(48.68)$ & $29(61.7)$ & \\
\hline
\end{tabular}


Table 1. Cont.

\begin{tabular}{|c|c|c|c|}
\hline \multirow[t]{2}{*}{ Variables } & $\begin{array}{c}\text { Not Exclusive Breastfeeding for } \\
6 \text { Months }\end{array}$ & $\begin{array}{l}\text { Exclusive Breastfeeding for } \\
6 \text { Months }\end{array}$ & \multirow[t]{2}{*}{${ }^{*} p$} \\
\hline & $n(\%)$ & $n(\%)$ & \\
\hline \multicolumn{4}{|c|}{ Social and Individual Maternal, Infant O Mother-Child Factors } \\
\hline \multicolumn{4}{|l|}{ MATERNITY LEAVE } \\
\hline without maternity leave & $84(44.44)$ & $26(55.3)$ & \multirow[t]{2}{*}{0.17} \\
\hline on maternity leave & $105(55.55)$ & $21(44.7)$ & \\
\hline \multicolumn{4}{|l|}{ SEX OF NEWBORN } \\
\hline Boy & $105(55.55)$ & $21(44.7)$ & \multirow[t]{2}{*}{0.17} \\
\hline Girl & $84(44.44)$ & $26(55.3)$ & \\
\hline \multicolumn{4}{|c|}{ CLINICAL FEATURES } \\
\hline \multicolumn{4}{|l|}{ PREVIOUS NUMBER OF } \\
\hline CHILDREN & & & \multirow{4}{*}{0.20} \\
\hline Neither & $83(44.15)$ & $23(48.9)$ & \\
\hline Only one & $80(42.33)$ & $22(46.8)$ & \\
\hline Two or more & $26(13.76)$ & $2(4.3)$ & \\
\hline \multicolumn{4}{|l|}{ DAYS OF GESTATION } \\
\hline$<280$ & $101(53.44)$ & $23(48.9)$ & \multirow[t]{2}{*}{0.55} \\
\hline$\geq 280$ & $88(46.56)$ & $24(51.1)$ & \\
\hline \multicolumn{4}{|l|}{ ANESTHESIA } \\
\hline without anesthesia & $28(14.81)$ & $5(10.6)$ & \multirow[t]{2}{*}{0.41} \\
\hline with anesthesia & $161(85.2)$ & $42(89.4)$ & \\
\hline \multicolumn{4}{|l|}{ BIRTH WEIGHT (kg) } \\
\hline$\leq 3.250$ & $91(48.1)$ & $21(44.7)$ & \multirow[t]{2}{*}{0.64} \\
\hline$>3.250$ & $98(51.9)$ & $26(55.3)$ & \\
\hline \multicolumn{4}{|l|}{ TYPE OF DELIVERY } \\
\hline $\begin{array}{l}\text { Vaginal with or whitout } \\
\text { instrumental }\end{array}$ & $145(76.7)$ & $36(76.6)$ & \multirow[t]{2}{*}{0.97} \\
\hline Cesarean section & $44(23.3)$ & $11(23.4)$ & \\
\hline \multicolumn{4}{|c|}{ HAVE DECIDED ON THE TYPE OF LACTATION PRIOR TO DELIVERY } \\
\hline Yes, breastfeeding & $173(91.5)$ & $47(100)$ & \multirow[t]{2}{*}{0.03} \\
\hline They haven't decided yet & $17(8.9)$ & $0(0.00)$ & \\
\hline DECISION O & HE DURATION TO CONTINUE TI & EASTFEEDING & \\
\hline One month & $2(1.1)$ & $0(0)$ & \\
\hline Two months & 0 & $0(0)$ & \\
\hline Three months & $2(1.1)$ & $0(0)$ & \\
\hline Between 3 and 6 month & $69(36.5)$ & $11(23.4)$ & 0.23 \\
\hline As long as the baby wants it & $18(9.5)$ & $7(14.9)$ & \\
\hline As long as I can & $86(45.5)$ & $29(61.7)$ & \\
\hline & RACTERISTICS OF THE CLINICA & FAMILY ENVIRONMENT & \\
\hline $\begin{array}{l}\text { BELIEVE THAT THE BABY IS } \\
\text { HUNGRY }\end{array}$ & & & \\
\hline The baby is satisfied & $118(62.4)$ & $39(83)$ & 0.00 \\
\hline $\begin{array}{c}\text { The baby isn't satisfied or I } \\
\text { have doubts }\end{array}$ & $71(37.6)$ & $8(17)$ & \\
\hline THEY OFF & ED BOTTLES OF WATER OR ORS & IE HOSPITAL & \\
\hline Yes & $73(38.6)$ & $26(55.3)$ & 0.04 \\
\hline Not & $116(61.4)$ & $21(44.7)$ & \\
\hline THEY OFFERED FORMULA & & & \\
\hline FEEDING & & & \\
\hline Not & $53(28.1)$ & $20(42.6)$ & 0.06 \\
\hline Yes & $136(71.9)$ & $27(57.4)$ & \\
\hline INITI & PRACTICE PROBLEMS WITH BRE & EEDING & \\
\hline Not & $155(82.1)$ & $36(76.6)$ & 0.38 \\
\hline Yes & $34(17.9)$ & $11(23.4)$ & \\
\hline & SOLVED THE BREASTFEEDING I & LEMS & \\
\hline Not & $81(42.9)$ & $23(48.9)$ & 0.47 \\
\hline Yes & $108(57.1)$ & $24(51.1)$ & \\
\hline
\end{tabular}


Table 1. Cont.

\begin{tabular}{|c|c|c|c|}
\hline \multirow[t]{2}{*}{ Variables } & $\begin{array}{c}\text { Not Exclusive Breastfeeding for } \\
6 \text { Months }\end{array}$ & $\begin{array}{l}\text { Exclusive Breastfeeding for } \\
6 \text { Months }\end{array}$ & \multirow[t]{2}{*}{${ }^{*} p$} \\
\hline & $n(\%)$ & $n(\%)$ & \\
\hline \multicolumn{4}{|c|}{ CHARACTERISTICS OF THE CLINICAL OR FAMILY ENVIRONMENT } \\
\hline \multicolumn{4}{|l|}{$\begin{array}{l}\text { BREASTFEEDING } \\
\text { COUNSELLING }\end{array}$} \\
\hline Not recivied or not necesary & $75(39.7)$ & $13(27.7)$ & 0.18 \\
\hline Search itself & $25(13.2)$ & $5(10.6)$ & \\
\hline $\begin{array}{l}\text { Health profesional or support } \\
\text { group }\end{array}$ & $89(47.01)$ & $29(61.7)$ & \\
\hline \multicolumn{4}{|c|}{ COUPLE OPINION REGARDING BREASTFEEDING } \\
\hline Not in favor & $3(1.6)$ & $0(0)$ & 0.08 \\
\hline In favor & $171(90.5)$ & $47(100)$ & \\
\hline Indifferent & $15(7.93)$ & $0(0)$ & \\
\hline
\end{tabular}

ORS $=$ oral rehydration solutions; ${ }^{*} p .=$ statistical significance.

Some variables ("pacifier use", "days of pregnancy", and "duration of BF in previous children") were analyzed independently because these variables could not be included in the multivariate model. The variable "duration of BF in previous children" did not apply to all women and only applied to those who previously had children. The other two variables were continuous and measured in days of EBF duration over 6 months (Table 2).

Table 2. Relationship between the other variables and the maintenance of exclusive breastfeeding for 6 months (women who practiced exclusive breastfeeding for some time during the 6 months).

\begin{tabular}{|c|c|c|c|c|}
\hline \multicolumn{5}{|c|}{ Relationship beteween Use of Pacifier and Time Achieved of EBF } \\
\hline Variables & $n(\%)$ & Time of EBF (Days) & SD & $x^{2}$ \\
\hline \multicolumn{5}{|l|}{ USE OF THE PACIFIER } \\
\hline Not use pacifier & $68(28.8)$ & 118.9 & 69.14 & \multirow{3}{*}{$<0.001$} \\
\hline Start using in the first 29 days & $67(28.4)$ & 57.19 & 67.42 & \\
\hline Start using from the first 30 days & $101(42.8)$ & 73.37 & 74.28 & \\
\hline \multicolumn{5}{|c|}{ RELATIONSHIP BETEWEEN AVERAGE NUMBER OF DAYS OF PREGNANCY AND TIME ACHIEVED OF EBF } \\
\hline VARIABLES & $n(\%)$ & $\begin{array}{c}\text { Time of pregnancy } \\
\text { (days) }\end{array}$ & SD & $\mathrm{t}$ \\
\hline \multicolumn{5}{|l|}{ EBF 3 MONTHS } \\
\hline NOT & $124(52.5)$ & 275.23 & 8.6 & \multirow[t]{2}{*}{0.001} \\
\hline YES & $112(47.45)$ & 277.93 & 7.6 & \\
\hline \multicolumn{5}{|l|}{ EBF 6 MONTHS } \\
\hline NOT & $190(88.5)$ & 275.99 & 8.47 & \multirow[t]{2}{*}{0.05} \\
\hline YES & $46(19.49)$ & 278.64 & 6.79 & \\
\hline \multicolumn{5}{|c|}{ RELATIONSHIP BETEWEEN PRIOR EXPERIENCE IN EBF AND MAINTENANCE OF EBF 6 MONTHS } \\
\hline VARIABLES & $n(\%)$ & $\begin{array}{c}\text { Maintenance of EBF } 6 \\
\text { months (OR) }\end{array}$ & CI 95\% & $p^{*}$ \\
\hline \multicolumn{5}{|l|}{ TIME OF EBF TO OTHERS } \\
\hline No time & $4(7.14)$ & Ref. & & \\
\hline Until 6 months & $7(13.73)$ & 2.205 & $(0.59-8.22)$ & 0.239 \\
\hline Over 6 months & $14(40)$ & 8.902 & $(2.60-30.4)$ & 0.00 \\
\hline
\end{tabular}

$\mathrm{EBF}=$ exclusive breastfeeding; $\mathrm{SD}=$ standard deviation; $\chi^{2}=$ Chi-square test; $\mathrm{t}=$ Student $\mathrm{t}$-test; $\mathrm{OR}=$ Odds ratio; $\mathrm{CI}=$ Confidence Interval; $p^{*}=$ statistical significance. 
A multivariate analysis was carried out to analyze all significant sociodemographic and clinical variables. In the resulting predictive model, only two variables predicted the cessation of EBF before 6 months (Table 3).

Table 3. Conditions influencing the cessation of exclusive breastfeeding at 6 months.

\begin{tabular}{|c|c|c|c|}
\hline Influential Variables & OR & IC $95 \%$ & ${ }^{*} p$ \\
\hline BELIEVE THE BABY IS NOT & & & \\
\hline $\begin{array}{l}\text { SATISFIED OR HAVING } \\
\text { DOUBTS }\end{array}$ & 2.96 & $(0.149-768)$ & 0.01 \\
\hline $\begin{array}{c}\text { HAVING OFFERED BOTTLES } \\
\text { OF WATER OR ORS }\end{array}$ & 0.52 & $(1.000-3.707)$ & 0.05 \\
\hline
\end{tabular}

OR = Odds Ratio, $\mathrm{CI}=$ Confidence interval, ${ }^{*} p=$ statistical significance.

The graphs shown in Figure 3 illustrate the Kaplan-Meier curves of the variables positively associated with the maintenance of EBF for up to 6 months.

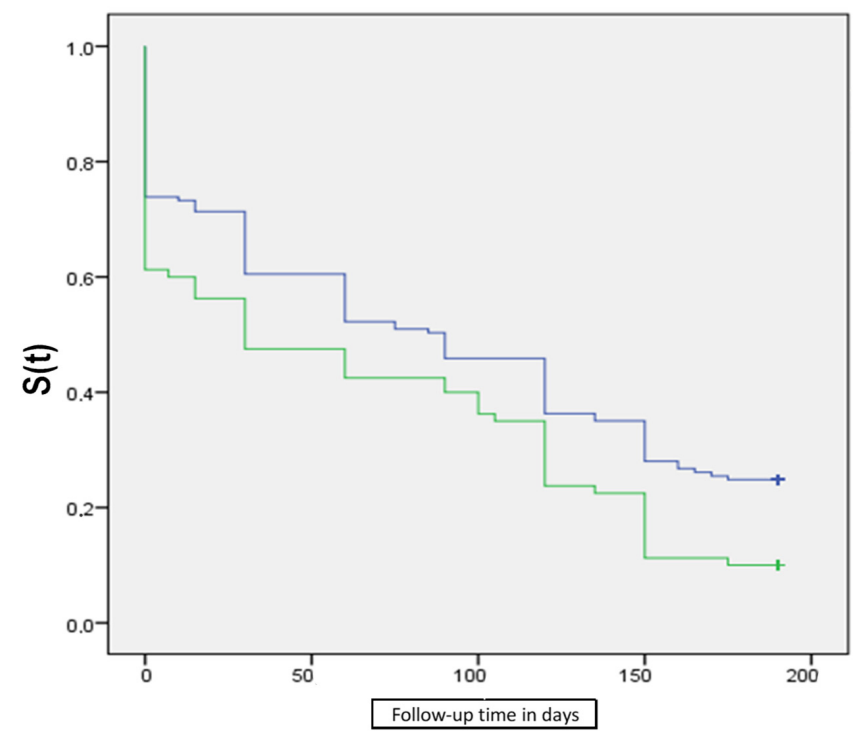

$\neg$ The mother believes that the baby is satisfied

$\neg \quad$ The mother believes that the baby isn't satisfied or she has doubts

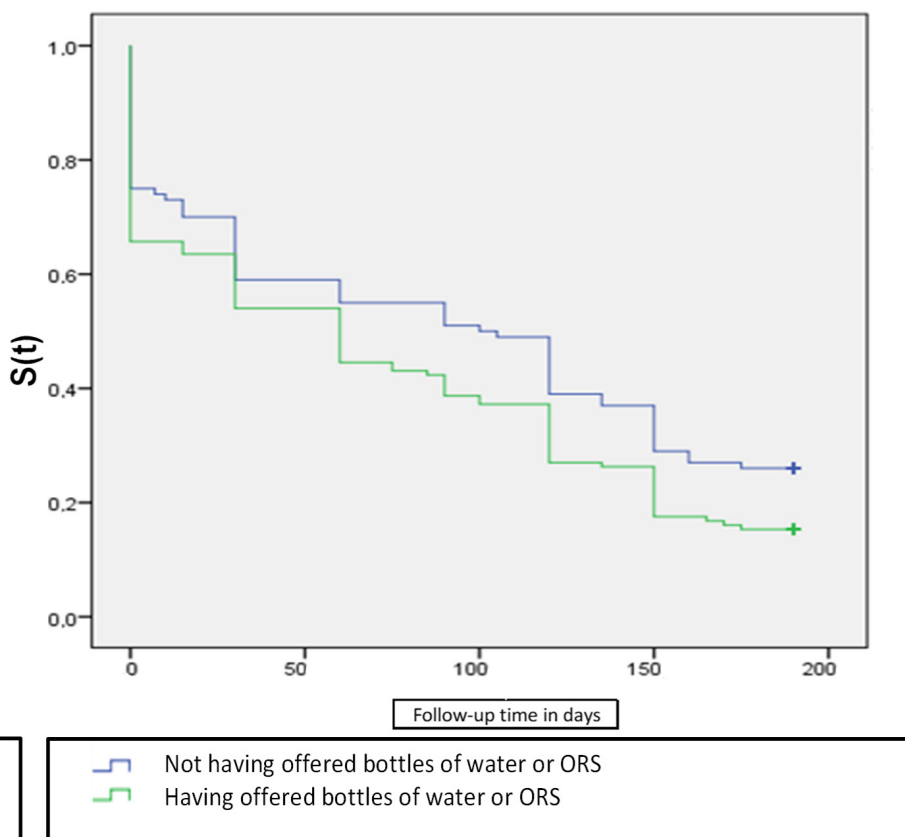

Figure 3. Kaplan-Meier curves of the duration of exclusive breastfeeding according to the mothers' beliefs and supplementation with water or ORS in the breastfeeding process.

\subsection{Early Cessation of EBF}

Table 4 shows the reasons mentioned by the mothers for stopping EBF before 6 months and their correlations with the duration of EBF.

Bivariate analyses were performed with each of the variables based on the different reasons mentioned by the mothers for early cessation of EBF. Variables that were found to be statistically significant were input into a multivariate analysis (Table 5). 
Table 4. Reasons for cessation and duration of exclusive breastfeeding (women who practiced exclusive breastfeeding).

\begin{tabular}{|c|c|c|c|c|}
\hline \multicolumn{2}{|c|}{ Reasons Aluded by the Mothers } & $n(\%)$ & Average Days of EBF & SD \\
\hline \multirow{6}{*}{$\begin{array}{l}\text { Reasons for } \\
\text { introducing artificial } \\
\text { milk bottles }\end{array}$} & Health recommendation & $7(2.9)$ & 115.7 & 41.3 \\
\hline & $\begin{array}{l}\text { Influence of social or } \\
\text { family environment }\end{array}$ & $11(4.6)$ & 107.8 & 51.5 \\
\hline & $\begin{array}{c}\text { The baby does not weight gain } \\
\text { according to standards }\end{array}$ & $4(1.6)$ & 97.5 & 58.1 \\
\hline & Labour problems & $24(10.1)$ & 96.0 & 40.2 \\
\hline & The baby gets hungry & $21(8.9)$ & 76.7 & 51.9 \\
\hline & Problems with breastfeeding & $27(11.4)$ & 60.8 & 49.8 \\
\hline Reasons for & Health recommendation & $84(35.6)$ & 100.4 & 55.1 \\
\hline introducing solid foods & She decides for herself & $7(2.9)$ & 105.7 & 60.2 \\
\hline
\end{tabular}

$\mathrm{EBF}=$ exclusive breastfeeding, $\mathrm{SD}=$ standard deviation.

Table 5. Reasons cited by mothers for ceasing exclusive breastfeeding. Multivariate analysis (women who practiced exclusive breastfeeding some time for 6 months).

\begin{tabular}{|c|c|c|c|c|}
\hline $\begin{array}{c}\text { Reasons for Introducing Artificial } \\
\text { Milk Bottles }\end{array}$ & $n(\%)$ & Average Days of EBF & SD & ${ }^{*} p$ \\
\hline $\begin{array}{l}\text { Influence of social or } \\
\text { family environment }\end{array}$ & $162(68.6)$ & 88.9 & 81.3 & \\
\hline Labour problems & $26(11)$ & 88.65 & 46.53 & 0.05 \\
\hline Health recommendation & $11(4.7)$ & 73.64 & 66.56 & \\
\hline $\begin{array}{c}\text { Autoeficacy }=\text { The baby gets hungry } \\
+ \text { not sufficient weight gain } \\
\text { according to standards }\end{array}$ & $38(16.1)$ & 52.63 & 56.98 & \\
\hline
\end{tabular}

$\mathrm{EBF}=$ Exclusive Breastfeeding, $\mathrm{SD}=$ standard deviation, ${ }^{*} p=$ statistical significance.

\section{Discussion}

This study, which was carried out in a region of Spain, found that the most influential factors and determinants of the duration of EBF during the first 6 months of life of a newborn were "previous experience with EBF", "delay in using a pacifier", and "longer gestation time". Many studies reported the factors influencing the maintenance of BF [17,18], but few studies explored the causes of cessation associated with the variables and reasons mentioned by the mothers [23-25].

\subsection{Prevalence of the Different Types of Breastfeeding Practiced in Our Setting}

The prevalence of EBF at 6 months after birth was $19.49 \%$ in our setting. This figure is well below the goals set at the international level [11,13]. According to the Breastfeeding Committee of the Spanish Association of Pediatrics, the worldwide prevalence of EBF reached $43 \%$ in 2015 [26]. In Spain, according to the latest National Health Survey (NHS) that preceded the study, in 2012, 28.5\% of children received EBF until 6 months of age [27]. In the NHS conducted after our study, in 2017, it was reported that $39 \%$ of women maintained EBF for up to 6 months, which is consistent with the WHO data [28,29]. The most recent study in our setting showed a prevalence of EBF of 35.1\% at hospital discharge without subsequent longitudinal data [30]. This finding implies a decrease of almost half compared to our results obtained at 1 month $(66.1 \%)$. Therefore, new studies describing and comparing the current prevalence of EBF with national and international figures and describing the involved characteristics and factors are necessary.

\subsection{Epidemiological Factors}

Our study shows similarities and discrepancies with the results found in other studies regarding the epidemiological factors associated with the maintenance of EBF for 6 months.

On the one hand, we did not find statistical significance for any of the sociodemographic variables studied. Some variables, such as a younger age, lower educational 
level, and maternal employment status [24,31], have been found to be major obstacles to prolonged EBF in similar studies and nearby settings. In our study, similar to the cohort studied by Gipúzcoa [24], age had no statistically significant effect. However, our results are consistent with other studies regarding older mothers being able to maintain BF for longer ( $72.3 \%$ vs. $27.7 \%)$. This finding may be due to greater knowledge of $\mathrm{BF}$ and more confidence and determination when searching for helpful resources. Employment has been associated with the duration of EBF in different studies not because women have a paid job or are unemployed but because the conditions that regulate and support this practice allow women to breastfeed with ease [24,31]. However, our study agrees with other studies showing that work is one of the most important reasons cited by mothers for ceasing BF early [32].

On the other hand, in contrast to other studies, our results do not show a statistically significant association $[33,34]$ between the type of delivery and maintenance of EBF for 6 months. Notably, compared to the women who delivered vaginally with or without instruments, almost one-third of the women who delivered by cesarean section maintained EBF for 6 months (26.4\% vs. $76.6 \%)$.

Our results show that $100 \%$ of mothers who decided to practice BF before delivery managed to maintain EBF until 6 months in contrast to those who did not. Other studies also argue that the prenatal decision to breastfeed increases the chances of initiating EBF $[24,35]$.

\subsection{Relationship between the Reasons for Cessation and Duration of Exclusive Breastfeeding}

The mothers reported several reasons for the early cessation of EBF that coincide with those found in other studies [24,32,36]. Again, our findings corroborate that women who experience problems with BF practice EBF for shorter durations. The same was observed in a study investigating the INMA birth cohort in 2015 [24]. Our findings agree with other studies that argue that maternal self-efficacy in BF is deficient and usually causes early BF cessation $[37,38]$.

In our study, $83 \%$ of the mothers who believed that their child remained hungry after breastfeeding and $55.3 \%$ who supplemented BF with water or ORS in the hospital after delivery failed to maintain EBF for 6 months. Both subjective hypogalactia and the maintenance of these erroneous practices are decisive in the correct maintenance of BF. This finding was also reported in other studies [31,39]. In addition, these two variables or conditions were found to predict early EBF cessation in this population.

Offering bottles of formula at the beginning has also been described as a barrier to the long-term maintenance of EBF [40,41]. In our study, $57.4 \%$ of the mothers did not manage to maintain EBF for 6 months, although this result was not statistically significant.

In the final multivariate model, maternal lack of confidence with the ability to breastfeed and raise the child correctly (also called breastfeeding self-efficacy) was the most important predictor of EBF cessation. These women practiced EBF for the fewest number of days over 6 months as also reported in one of the largest studies conducted in Spain [36]. Work-related reasons along with pressure from the family and/or social environment were also predictive factors of cessation mentioned as important by mothers, which is consistent with other studies $[24,32,38,42]$. Similarly, in our predictive model, both reasons were decisive but not the most important. However, these reasons were associated with the longest duration of EBF and the EBF rate at 6 months.

\subsection{Implications for Clinical Practice}

Given that all women who decided before giving birth to practice BF maintained BF for 6 months, it may be relevant for health professionals to train and promote BF in childbirth preparation classes. The benefits of $\mathrm{BF}$ and the factors that can influence early cessation should be emphasized. In addition, it has been demonstrated that the implementation of the Baby-friendly Hospital Initiative (BFHI) is key to enhancing support to pregnant women, mothers and families and positively influencing at least the initiation of EBF [43]. 
Scientific evidence has shown that good training and providing help and support to mothers improves the initiation and maintenance of EBF [28,32,44,45]. Although without statistical significance, our study also showed a higher rate of EBF at 6 months $(61.7 \%)$ when the mothers received advice from health professionals or BF support groups than when they did not $(10.6 \%)$. Similarly, the women who did not have problems with BF at the beginning also showed higher rates of EBF at 6 months than those who did (76.6\% vs. 23.4\%).

\subsection{Limitations and Strengths}

The main limitations of this study are the loss to follow-up of some women in the initial sample. Because an ad hoc questionnaire was used in the study, it may not have the reliability of a validated questionnaire. However, at the time of the study, there was still no validated questionnaire for the Spanish population. The strength of this study is the fact that it was a longitudinal study with data collected from the same women over 6 months.

\section{Conclusions}

Despite the efforts, the rates of EBF at 6 months in our setting were low.

Our results show that ceasing EBF before 6 months is determined by the following two factors: having offered bottles with water or ORS to the child and maintaining the belief that the child remains hungry after BF. The long-term maintenance of EBF is related to having previously decided to practice $\mathrm{BF}$, having previous experience with $\mathrm{EBF}$, not carrying out practices that interfere with $\mathrm{BF}$ (e.g., supplementation or pacifier use), and a longer gestation time.

The main reasons for the early cessation of EBF reported by the mothers, which were significant factors, were (a) social or family environment influence, (b) work problems, (c) recommendations by health professionals, and (d) self-efficacy (believing that the child remains hungry after $\mathrm{BF}$ or is not gaining weight according to the standard).

It is necessary to continue evaluating whether the BF strategies carried out in our setting in recent years are effective not only for enhancing the EBF initiation rates but also for increasing the percentages of mothers who maintain EBF over time.

Author Contributions: Conceptualization, E.S.-S., A.I.C.-C., and A.S.-F.; methodology, J.M.C.-T. and A.I.C.-C.; software, A.S.-F. and J.M.C.-T.; validation, A.S.-F., E.S.-S., D.P.P.-C., and J.A.L.-A.; formal analysis, A.S.-F. and J.M.C.-T.; investigation, E.S.-S. and A.I.C.-C.; resources, A.S.-F., J.A.L.-A., D.P.P.C., E.S.-S., and A.I.C.-C.; data curation, J.A.L.-A. and J.M.C.-T., and A.I.C.-C.; writing-original draft preparation, J.M.C.-T., A.I.C.-C., and E.S.-S.; writing-review and editing, J.A.L.-A., A.I.C.-C., E.S.-S., and D.P.P.-C.; visualization, A.I.C.-C.; supervision, A.I.C.-C., J.A.L.-A., E.S.-S., D.P.P.-C., and J.M.C.-T.; project administration, J.A.L.-A.; and funding acquisition, J.A.L.-A., D.P.P.-C., A.I.C.-C., J.M.C.-T., and E.S.-S. All authors have read and agreed to the published version of the manuscript.

Funding: This research was funded by a grant from the European Regional Development Fund (ERDF) (Fondo Europeo de Desarrollo Regional (FEDER), (DOCM 26/02/20)).

Institutional Review Board Statement: The project was conducted according to the guidelines of the Declaration of Helsinki and assessed by the Clinical Research Ethics Committee of the hospital (CEITO. number: 74. Date: 6/06/2014).

Informed Consent Statement: The necessary informed consent was obtained in writing after each participant was informed of the objectives and methodology of the study.

Data Availability Statement: The data that support the findings of this study are available from the corresponding author, upon reasonable request.

Conflicts of Interest: The authors declare no conflict of interest.

\section{References}

1. WHO. Indicators for Assessing Infant and Young Child Feeding Practices: Part 2: Measurement; WHO: Geneva, Switzerland, 2010.

2. Morales, E.; García-Esteban, R.; Guxens, M.; Guerra, S.; Mendez, M.; Moltó-Puigmartí, C.; Lopez-Sabater, M.C.; Sunyer, J. Effects of prolonged breastfeeding and colostrum fatty acids on allergic manifestations and infections in infancy. Clin. Exp. Allergy 2012, 42, 918-928. [CrossRef] 
3. Robinson, S.; Fall, C. Infant nutrition and later health: A review of current evidence. Nutrients 2012, 4, 859-874. [CrossRef]

4. Brahm, P.; Valdes, V. Benefits of breastfeeding and risks associated with not breastfeeding. Rev. Chil. Pediatr. 2017, 88, 15-21.

5. Gartner, L.M.; Morton, J.; Lawrence, R.A.; Naylor, A.J.; O’Hare, D.; Schanler, R.J.; Eidelman, A.I.; American Academy of Pediatrics Section on Breastfeedingl. Breastfeeding and the use of human milk. Pediatrics 2005, 115, 496-506.

6. Holme, A.; MacArthur, C.; Lancashire, R. The effects of breastfeeding on cognitive and neurological development of children at 9 years. Child. Care Health Dev. 2010, 36, 583-590. [CrossRef]

7. WHO; OPS/WHO Guatemala. First Series 2016 on Breastfeeding. Spanish Edition, Guatemala. Lancet 2016, 387, $475-504$.

8. Victora, C.G.; Bahl, R.; Barros, A.J.D.; Franca, G.V.A.; Horton, S.; Krasevec, J.; Murch, S.; Sankar, M.J.; Walker, N.; Rollins, N.C. Lancet Breastfeeding Series Group. Breastfeeding in the 21st Century: Epidemiology, mechanisms and lifelong effect. Lancet 2016, 387, 475-490. [CrossRef]

9. Bartick, M.; Reinhold, A. The burden of suboptimal breast feeding in the United States: A pediatric cost analysis. Pediatrics 2010, 125, 1048-1056. [CrossRef] [PubMed]

10. Santacruz-Salas, E.; Aranda-Reneo, I.; Hidalgo-Vega, Á.; Blanco-Rodriguez, J.M.; Segura-Fragoso, A. The Economic Influence of Breastfeeding on the Health Cost of Newborns. J. Hum. Lact. 2018. [CrossRef] [PubMed]

11. WHO. Comprehensive Implementacion Plan. on Maternal Infant and Young Child. Nutritional; World Health Organization: Geneva, Switzerland, 2014.

12. WHO; Unicef. Implementing the Global Strategy for Infant and Young Child. Feeding: Geneva, 3-5 February 2003: Meeting Report; World Health Organization: Geneva, Switzerland, 2003.

13. OMS. World Health Organization. Global Nutrition Targets 2025: Breastfeeding Policy Brief. No. WHO/NMH/NHD/14.7. World Health Organization. 2014. Available online: https://apps.who.int/iris/bitstream/handle/10665/149022/WHO_NMH_ NHD_14.7_eng.pdf (accessed on 20 April 2021).

14. Lim, S.S.; Vos, T.; Flaxman, A.D.; Danaei, G.; Shibuya, K.; Adair-Rohani, H.; AlMazroa, M.A.; Amann, M.; Anderson, H.R.; Andrews, K.G.; et al. A comparative risk assessment of burden of disease and injury attributable to 67 risk factors and risk factor clusters in 21 regions, 1990-2010: A systematic analysis for the Global Burden of Disease Study 2010. Lancet 2012, 380, $2224-2260$. [CrossRef]

15. Rollins, N.C.; Bhandari, N.; Hajeebhoy, N.; Horton, S.; Lutter, C.K.; Martines, J.C.; Piwoz, E.G.; Richter, L.M.; Victora, C.G. Lancet Breastfeeding Series Group. Why invest, and what it will take to improve breastfeeding practices? Lancet 2016, 387, 491-504. [CrossRef]

16. Santacruz-Salas, E.; Aranda-Reneo, I.; Segura-Fragoso, A.; Cobo-Cuenca, A.I.; Laredo-Aguilera, J.A.; Carmona-Torres, J.M. Mothers' Expectations and Factors Influencing Exclusive Breastfeeding during the First 6 Months. Int J. Environ. Res. Public Health 2019, 17, 77. [CrossRef]

17. Villar, M.; Santa-Marina, L.; Murcia, M.; Amiano, P.; Gimeno, S.; Ballester, F.; Julvez, J.; Romaguera, D.; Fernández-Somoano, A.; Tardón, A.; et al. Social Factors Associated with Non-initiation and Cessation of Predominant Breastfeeding in a Mother-Child Cohort in Spain. Matern. Child. Health J. 2018, 22, 725-734. [CrossRef] [PubMed]

18. Lechosa-Muñiz, C.; Paz-Zulueta, M.; Sota, S.M.; de Adana Herrero, M.S.; del Rio, E.C.; Llorca, J.; Cabero-Perez, M.J. Factors associated with duration of breastfeeding in Spain: A cohort study. Int. Breastfeed. J. 2020, 15, 79. [CrossRef]

19. Ruiz Poyato Pablo y Juan Miguel Martínez Galiano. Causas del abandono de la lactancia materna exclusiva en una zona básica urbana. Ene 2014, 8. Available online: http:/ / scielo.isciii.es/scielo.php?script=sci_arttext\&pid=S1988-348X2014000200004\&lng=es (accessed on 21 April 2021).

20. Ballesta-Castillejos, A.; Gomez-Salgado, J.; Rodriguez-Almagro, J.; Ortiz-Esquinas, I.; Hernandez-Martinez, A. Relationship between maternal body mass index with the onset of breastfeeding and its associated problems: An online survey. Int. Breastfeed. J. 2020, 15, 55. [CrossRef] [PubMed]

21. Ballesta-Castillejos, A.; Gómez-Salgado, J.; Rodríguez-Almagro, J.; Ortiz-Esquinas, I.; Hernández-Martínez, A. Factors that influence mothers' prenatal decision to breastfeed in Spain. Int. Breastfeed. J. 2020, 15, 97. [CrossRef]

22. Santacruz-Salas, E.; Segura-Fragoso, A.; Cobo-Cuenca, A.I.; Carmona-Torres, J.M.; Pozuelo-Carrascosa, D.P.; Laredo-Aguilera, J.A. Factors Associated with the Abandonment of Exclusive Breastfeeding before Three Months. Children 2020, 7, 298. [CrossRef]

23. Camargo Figuera, F.; Latorre Latorre, J.F.; Porras Carreño, J.A. Factores asociados al abandono de la lactancia materna exclusiva. Rev. Hacia Promoción Salud. 2011, 16, 56-72.

24. Oribe, M.; Lertxundi, A.; Basterrechea, M.; Begiristain, H.; Santa Marina, L.; Villar, M.; Dorronsoro, M.; Amiano, P.; Ibarluzea, J. Prevalence of factors associated with the duration of exclusive breastfeeding during the first 6 months of life in the INMA birth cohort in Gipuzkoa. Gac Sanit. 2015, 29, 4-9. [CrossRef]

25. Santo, L.C.D.E.; De Oliveira, L.D.; Giugliani, E.R.J. Factors associated with low incidence of exclusive breastfeeding for the first 6 months. Birth 2007, 34, 212-219. [CrossRef]

26. AEP. Lactancia Materna en Cifras: Tasas de Inicio y Duración de la Lactancia en España y en Otros Países: Asociación Española de Pediatría. 2016. Available online: https://www.aeped.es/sites/default/files/documentos/201602-lactancia-materna-cifras.pdf (accessed on 8 May 2021).

27. INE. Tipo de Lactancia Por Clase Social Basada en la Ocupación de la Persona de Referencia y Duración. 2011-2012 [Internet] 2013. Available online: http:/ / www.ine.es/jaxi/tabla.do?path=/t00/mujeres_hombres $/$ tablas_1 $/ 10 / \& f i l e=d 06003 p x \& t y p e=$ pcaxis\&L=0 (accessed on 8 May 2021). 
28. WHO. 10 Facts About Breastfeeding Internet 2017 35. Available online: https://www.who.int/features/factfiles/breastfeeding/es/ (accessed on 20 April 2021).

29. ENSE. Encuesta Nacional de Salud España 2017 [Internet]. Ministerio de Sanidad, Consumo y Bienestar Social 2018. Available online: https://www.mscbs.gob.es/estadEstudios/estadisticas/encuestaNacional/encuestaNac2017/ENSE17_pres_wEBF.pdf (accessed on 20 April 2021).

30. Alía, P.H.; Armenteros, P.C.; Pino Pino, N. Prevalencia y factores asociados de la lactancia materna exclusiva al alta en el Hospital Virgen de la Salud de Toledo. Matronas Hoy 2020, 8, 28-35.

31. Alvarez Caballero, M.; Orozco Hechavarría, N.; Moreno Alvarez, A.; Marín Álvarez, T.; Tur Vaillant, I. Factores que influyeron en el abandono precoz de la lactancia materna en lactantes de un Grupo Básico de Trabajo. Rev. Médica Electrónica 2017, 39, 884-893.

32. Balogun, O.O.; Dagvadorj, A.; Anigo, K.M.; Ota, E.; Sasaki, S. Factors influencing breastfeeding exclusivity during the first 6 months of life in developing countries: A quantitative and qualitative systematic review. Matern. Child Nutr. 2015, 11, 433-451. [CrossRef]

33. Chandrashekhar, T.S.; Joshi, H.S.; Binu, V.; Shankar, P.R.; Rana, M.S.; Ramachandran, U. Breast-feeding initiation and determinants of exclusive breast-feeding-a questionnaire survey in an urban population of western Nepal. Public Health Nutr. 2007, 10, 192-197. [CrossRef] [PubMed]

34. Yngve, A.; Sjöström, M. Breastfeeding determinants and a suggested framework for action in Europe. Public Health Nutr. 2001, 4, 729-739. [CrossRef] [PubMed]

35. Pinto, E.; Chaves, C.; Duarte, J.; Nelas, P.; Coutinho, E. Maternal Affection and Motivation for Breastfeeding. Procedia Soc. Behav. Sci. 2016, 217, 1028-1035. [CrossRef]

36. Díaz-Gómez, N.M.; Ruzafa-Martínez, M.; Ares, S.; Espiga, I.; De Alba, C. Motivaciones y Barreras Perci-Bidas Por Las Mujeres Españolas en Relación a la Lactancia Materna. Revista Española de Salud Pública 2016, 90. Available online: https://scielo.isciii.es/ scielo.php?pid=S1135-57272016000100416\&script=sci_arttext\&tlng=pt (accessed on 2 May 2021).

37. Walker, M. Breastfeeding Management for the Clinician: Using the Evidence; Jones \& Bartlett Publishers: Burlington, MA, USA, 2013.

38. Roig, A.O.; Martínez, M.R.; García, J.C.; Hoyos, S.P.; Navidad, G.L.; Alvarez, J.C.F.; Pujalte, M.D.M.C.; González, R.G.D.L. Factors associated to breastfeeding cessation before 6 months. Rev. Lat. Am. Enferm. 2010, 18, 373-380. [CrossRef]

39. Erkkola, M.; Salmenhaara, M.; Kronberg-Kippilä, C.; Ahonen, S.; Arkkola, T.; Uusitalo, L.; Pietinen, P.; Veijola, R.; Knip, M.; Virtanen, S.M. Determinants of breast-feeding in a Finnish birth cohort. Public Health Nutr. 2010, 13, 504-513. [CrossRef]

40. Cervera-Gasch, Á.; Mena-Tudela, D.; Leon-Larios, F.; Felip-Galvan, N.; Rochdi-Lahniche, S.; Andreu-Pejó, L.; González-Chordá, V.M. Female Employees' Perception of Breastfeeding Support in the Workplace, Public Universities in Spain: A Multicentric Comparative Study. Int. J. Environ. Res. Public Health 2020, 17, 6402. [CrossRef] [PubMed]

41. Renfrew, M.J.; McCormick, F.M.; Wade, A.; Quinn, B.; Dowswell, T. Support for healthy breastfeeding mothers with healthy term babies. Cochrane Database Syst. Rev. 2012. [CrossRef]

42. Wong, M.S.; Huanyu, M.; Wai, T.C. Effectiveness of educational and supportive intervention for primiparous women on breastfeeding related outcomes and breastfeeding self-efficacy: A systematic review and meta-analysis. Int. J. Nurs. Studies 2021, 103874. Available online: https:/ /www.sciencedirect.com/science/article/pii/S0020748921000067?casa_token=FMJfaaYyIEoAAAAA:7Hle8fn214 NHmemmTrCnGFbrbasNVtsn3fFZ2IqKCJWUglqCh51CI669A858vS4GfuopB8F_ (accessed on 18 April 2021). [CrossRef]

43. Philipp, B.L.; Merewood, A.; Miller, L.W.; Chawla, N.; Murphy-Smith, M.M.; Gomes, J.S.; Cimo, S.; Cook, J.T. Baby-friendly hospital initiative improves breastfeeding initiation rates in a US hospital setting. Pediatrics 2001, 108, 677-681. [CrossRef] [PubMed]

44. Ruiz Navas, L. Causes of the Abandonment of Breastfeeding in Spain (2005-2015) Bibliographic Review. [Final degree project on the Internet]. [Nursing Faculty of Soria] University of Valladolid. 2019. Available online: http://uvadoc.uva.es/handle/10324/39125 (accessed on 24 April 2021).

45. Vila-Candel, R.; Soriano-Vidal, F.J.; Murillo-Llorente, M.; Pérez-Bermejo, M.; Castro-Sánchez, E. Mantenimiento de la lactancia materna exclusiva a los 3 meses posparto: Experiencia en un departamento de salud de la Comunidad Valenciana. Atención Primaria 2019, 51, 91-98. [CrossRef] 